\title{
The role of HPV in head and neck cancer and review of the HPV vaccine
}

\author{
Gypsyamber D'Souzaa, ${ }^{\star}$ and Amanda Dempsey ${ }^{b}$ \\ aJohns Hopkins Bloomberg School of Public Health, Department of Epidemiology, USA \\ bUniversity of Michigan, Department of Pediatrics, USA
}

\section{Abstract}

Recent data demonstrate that human papillomavirus also plays a role in cancers other than anogenital cancers, specifically head and neck cancers, and non-cancerous conditions such as recurrent respiratory papillomatosis. As more and more information about the role of infection in non-cervical diseases is amassed, additional questions about whether prophylactic human papillomavirus vaccines will effectively prevent these conditions are raised. This article reviews the epidemiology of oral human papillomavirus infection and the role of human papillomavirus in head and neck cancers. In addition, it will review the known clinical indications for human papillomavirus vaccination, and highlight other potential clinical targets for the vaccine that have not yet been demonstrated in clinical trials but for which there is biologic plausibility.

\section{Keywords}

Human papillomavirus; Vaccine; Clinical trials; Epidemiology; Respiratory papillomatosis; Genital warts; Squamous cell carcinoma; Anal cancer

\section{Epidemiology of HPV-associated head and neck cancer}

\section{Role of HPV in head and neck cancers}

Over the last decade it has become clear that human papillomavirus (HPV) not only causes genital and anal cancers, but also causes a subset of head and neck squamous cell carcinoma (HNSCC). In addition to the estimated $\sim 492,800$ cervical cancers caused worldwide by HPV each year, HPV also causes an estimated $\sim 30,000$ oropharyngeal cancers, HPV is detected in $\sim 25 \%$ of all HNSCC (Kreimer et al., 2005), and the majority of these HPV-associated HNSCC are oropharyngeal (tonsillar and base of tongue) squamous cell cancers. In fact, HPV is now the major cause of oropharyngeal cancer in developed countries, detected in 45-90\% of cases (Fig. 1) (D’Souza et al., 2007a; Kreimer et al., 2005; Nasman et al., 2009). HPV has also been detected in a smaller subset of laryngeal (24\%) and oral cavity (23\%) cancers (Kreimer et al., 2005). There is strong and consistent molecular evidence demonstrating that HPV is an etiological cause of these oropharyngeal cancers. HPV is detected in the tumor of these oropharyngeal cancers, where it is localized to the cell nuclei,

\footnotetext{
(C) 2011 Published by Elsevier Inc.

"Corresponding author at: Johns Hopkins School of Public Health, 615 N Wolfe St. E6132, Baltimore, MD 21205, USA. Fax:+1 410 614 2635., gdsouza@jhsph.edu (G. D’Souza).

Conflict of interest statement

The authors have received research support from a consultant for Merck Inc. Amanda Dempsey serves as an advisory board consultant regarding implementation of male HPV vaccination for Merck, a maker of HPV vaccine. Merck does not support any of Dr.

Dempsey's research. Merck played no role in the development of content for this article.
} 
transcriptionally active, clonal, and not found in the surrounding benign tissue (Gillison et al., 2000). Epidemiologic evidence for the role of HPV in oropharyngeal cancer is equally strong. Case-control studies consistently show that oropharyngeal cancer cases have a higher average number of lifetime sexual partners (a surrogate for oral HPV exposure) and are more likely to have current oral HPV infection than matched controls (Gillison et al., 2008a; Heck et al., 2010; Schwartz et al., 1998).

While HPV is an important cause of oropharyngeal cancer, it is currently unclear whether HPV may also have a role in other head and neck cancers sub-sites. HPV has been detected in a subset of oral cavity and larynx cancers in several studies (Hobbs et al., 2006; Kreimer et al., 2005), although the proportion of these cancers that are HPV-associated is notably smaller than that observed for oropharyngeal cancer. It is currently unclear whether HPV has a causal role in these other head and neck cancers sub-sites or may be explained by subsite misclassification or undiagnosed oropharyngeal involvement.

\section{Changing epidemiology of HPV-associated head and neck cancer}

The epidemiology of head and neck squamous cell carcinoma (HNSCC) has changed dramatically over the past two decades. As tobacco use, traditionally the most important risk factor for HNSCC, has decreased in the U.S., the incidence of tobacco-associated HPVunrelated HNSC has also decreased (Chaturvedi et al., 2008; Ryerson et al., 2008). In stark contrast, the incidence of HPV-associated oropharyngeal cancers overall is increasing (Auluck et al., 2010; Chaturvedi et al., 2008; Hammarstedt et al., 2007; Hocking et al., 2011; Ryerson et al., 2008). In the U.S., the increase in oropharyngeal cancers has been observed primarily among men under age 60, where the incidence of tonsillar cancer increased 2-3\% each year between 1973 and 1995 (Frisch et al., 2000), and appears to have increased even more rapidly in the past decade (Chaturvedi et al., 2008; Marur et al., 2010). In some other countries an increase in oropharyngeal cancer incidence has been noted in both men and women (Auluck et al., 2010; Hocking et al., 2011). The fact that oropharyngeal cancer rates in the U.S. are increasing despite a decrease in tobacco use (Pierce et al., 2011), is striking. During 2000-2009 current tobacco use decreased among middle school (15\% to 8.2\%) and high school (35\% to 24\%) students in the U.S. (Centers for Disease Control and Prevention (CDC), 2010a), suggesting that prevalence of tobacco use in the U.S. may continue to decrease.

These data suggest that HPV has emerged as an increasingly important cause of oropharyngeal cancer not only because tobacco-associated HNSCC's have decreased, but also because the incidence of HPV-associated oropharyngeal cancers is increasing. A study in Sweden tested banked oropharyngeal tumor samples for HPV to evaluate how common HPV detection in these cancers was over several decades. This study showed that the proportion of tonsillar cancers associated with HPV increased dramatically from only $23 \%$ of oropharyngeal cancers in the 1970's to 28\% in the 1980's and then to 57\% of all oropharyngeal cancers in Sweden by the 1990's (Nasman et al., 2009). In the past decade this trend continued with $68 \%, 77 \%$, and $93 \%$ of oropharyngeal cancers in Sweden being associated with HPV during 2000-02, 2003-05 and 2006-07, respectively (Nasman et al., 2009). Similar increases have been reported for base of tongue cancers (Attner et al., 2010). In the U.S. the majority of oropharyngeal cancers are also now associated with HPV as well (Fig. 1). Only 16\% of U.S. oropharyngeal cases had HPV detected in 1984-1989 compared to $73 \%$ during 2000-2004, a four-fold increase in only two decades (Chaturvedi et al., 2011). This change does not appear to be related to the integrity of the tumor samples and appears instead to reflect an actual change in the etiology of this disease.

Survival of HPV-positive HNSCC patients is notably better than survival of HPV-negative HNSCC patients (three-year survival of $84 \%$ vs. 57\%, respectively) (Ang et al., 2010). 
Recent analysis of oropharyngeal cancer patient survival among cases from 1984 to 2004 in SEER suggested that median survival was four fold higher among HPV-positive than HPVnegative oropharyngeal cases (131 vs. 20 months) in the U.S during the past two decades. In addition, while survival increased significantly for HPV-positive oropharyngeal cases between 1984 and 2004 ( $\mathrm{p}=0.003$ ) survival did not improve for HPV-negative cases $(\mathrm{p}=0.18)$ (Chaturvedi et al., 2011).

Interestingly, the incidence of both HPV-associated and HPV-unassociated HNSCC is more than two-fold higher among men than women (Chaturvedi et al., 2008). Higher rates of heavy smoking and alcohol abuse among men are thought to drive the higher incidence of HPV-unassociated HNSCC in men. It is less clear why the incidence of HPV-associated HNSCC is substantially higher among men than women. Both cervical (Ho et al., 1998) and penile (Giuliano et al., 2011a; Nielson et al., 2007) HPV infection is common, despite the much lower incidence of penile than cervical cancers. One hypothesis is that HPV burden (copy number) might be higher in the vagina/cervix than the penis, and that individuals may be more likely to acquire an oral HPV infection when performing oral sex on a woman than on a man. It is unclear whether this is the case, although plausibility is supported by one recent study suggesting that HPV transmission during vaginal sex is more common from an infected cervix to the penis than from an infected penis to the cervix (Hernandez et al., 2008). HIV-infected individuals have also been noted to be at 2-6-fold increased risk of HPV-associated HNSCC (Engels et al., 2008; Gillison, 2009).

\section{Changes in sexual behavior}

Understanding what is driving the increasing incidence of HPV-associated HNSCC is of interest, and changes in sexual behaviors have been speculated as a possible reason. Although data on generational changes in sexual behaviors is limited, initial studies in both Europe and the U.S. suggest that the age of sexual debut has decreased and the lifetime number of sexual partners has increased over the past several decades (Agius et al., 2010; Aral et al., 2005; Bajos et al., 2010; Herlitz, 2009; Satterwhite et al., 2007; Turner et al., 1995). For example, studies in the U.S. suggest the proportion of women who reported having sex before age 18 increased from $<10 \%$ in $1900-1920$ 's to $25 \%$ during the 1930 40 's, $45 \%$ in 1950-60's, and 60\% in the 1970's (Turner et al., 1995). An increase in sexual risk-taking (i.e. more sexual partners and/or more oral sex with partners) in the 1960's and 1970's could have led to increased oral HPV exposure. A recent large U.S. study reported that ever having performed oral sex was common among women and men, but appeared to be more common among individuals 30-49 years of age than older generations. Specifically having ever performed oral sex was reported by $86 \%$ of 30-40 year old men, but only $74 \%$, and $62 \%$ of men ages 50-69 and 70 years or older. A similar trend was observed among women, with reports of ever performed oral sex by $82 \%, 77 \%$, and $43 \%$ of women ages 30 49, 50-69 and 70 years or older (Herbenick et al., 2010).

As HPV infection usually takes more than 10 years to progress from infection to malignancy, a temporal change in sexual behavior could explain the increased incidence observed in these cancers one and two decades later. More recent studies in the U.S. suggest that this trend of increasing sexual risk-taking may have changed. Between 1991 and 2009 the proportion of adolescents who had ever had intercourse significantly decreased from 54\% of teenagers in 1991 to 46\% in 2009 (Eaton et al., 2011; Santelli et al., 2000, 2009; Warren et al., 1998). Similar reductions have been seen in the proportion of US adolescents having had more than one sexual partner, and contraceptive use among sexually active adolescents has improved (Santelli et al., 2000, 2009). 


\section{Epidemiology of oral HPV infection \\ Oral HPV prevalence and natural history}

While it is now clear that HPV is an important cause of oropharyngeal cancer, risk factors for oral HPV infection and the natural history of infection are not as well understood. Oral HPV infection (as measured by HPV DNA detection in exfoliated oral cells from an oral rinse or swab) is uncommon ( $\leq 1 \%$ prevalence) in children (Smith et al., 2007), although one study reported higher rates ( 15\%) among infants (Rintala et al., 2005). HPV acquisition appears to increase around sexual debut with prevalent oral HPV detected in 1.5\% of 12-15 year olds and 3.3\% of 16-20 year olds (D'Souza et al., 2009; Smith et al., 2007). Oral HPV prevalence is higher among adults, detected in $\sim 4.5 \%$ of healthy adults (Kreimer et al., 2010a). Higher oral HPV prevalence has been reported in women with cervical HPV infection (Fakhry et al., 2006; Termine et al., 2011), and people infected with Human Immunodeficiency Virus (HIV) (Fakhry et al., 2006; Kreimer et al., 2004). Oral HPV16 prevalence (the HPV type responsible for $>85 \%$ of all HPV-associated HNSCC) is found in $1.3 \%$ of healthy adults (Kreimer et al., 2010a).

Initial oral HPV natural history studies suggest that oral HPV persistence is similar to that known for anogenital HPV infection (D'Souza et al., 2007b; Fakhry et al., 2010), and that most prevalent infections clear within a year on their own (Kreimer et al., 2010b). More longitudinal research is needed to better understand transmission of oral HPV infections, how likely infections are to clear, and what factors are associated with persistence. Some dental offices are now providing "oral cancer screening tests" where saliva is tested for HPV DNA. Unfortunately the sensitivity and specificity of HPV DNA detection in oral rinse or saliva samples for oral pre-cancer/cancer are unknown. Therefore the utility of oral HPV testing as an oral cancer screening tool is currently unclear.

\section{Risk factors for oral HPV}

Sexual behavior has consistently been associated with increased oral HPV prevalence, supporting the sexual transmission of the virus. As sexual behaviors are co-linear (people who have a higher number of partners for one type of sexual act often have a higher number of partners for other sexual acts), it can be difficult to differentiate which behaviors transmit HPV infection to the oral cavity/oropharynx. In cross-sectional studies, oral HPV prevalence is consistently associated with number of oral sex partners, suggesting it is likely HPV that may be transmitted by performing oral sex. However, partner studies are needed to understand how common transmission is and whether HPV can be transmitted to the mouth in other ways.

It is currently unclear whether HPV can be casually transmitted (i.e. transmitted nonsexually) to the oral cavity. Open-mouth kissing (French kissing) was associated with oral HPV prevalence in a small study of college men by our group (D'Souza et al., 2009), but not in another study of adults (unpublished results) and needs to be further evaluated. Oral HPV infection is uncommon in children (Smith et al., 2007), including those born to women with vaginal HPV infection (Saini et al., 2010). Concordance (agreement) of oral and cervical HPV infections is low (Fakhry et al., 2006; Smith et al., 2004b; Termine et al., 2011) suggesting that auto-inoculation of infection from one site to another within the same individuals is uncommon. However, one family study found persistent oral HPV infection in mothers was associated with increased risk of persistent oral HPV infection in their infants, suggesting that non-sexual transmission might occur (Rintala et al., 2005). Longitudinal partners studies demonstrating oral HPV transmission between partners have not yet been performed, however, a study of pregnant women and their spouses found that oral HPV infection in one spouse was associated with a four-fold increase in odds of oral HPV 
infection in the other spouse. Persistent oral HPV infection in one spouse was associated with a ten-fold increased risk of persistent infection in the other spouse (Rintala et al., 2006). In addition, partners of women with cervical cancer also have a higher incidence of tonsillar cancer than the general population (Hemminki et al., 2000), supporting again the possibility of transmission from the cervix of an infected women to the oral cavity/oropharynx during oral sex.

In addition to the strong association with sexual behavior, several other risk factors have been consistently associated with increased odds of prevalent oral HPV in initial cross sectional studies (Table 1). Current smoking and HIV-infection are both associated with significantly increased oral HPV prevalence, suggesting that tobacco-related and HIVrelated immunosupression may impact oral HPV natural history (i.e. make infections more likely to persist). Oral HPV prevalence remained higher in men than women in several studies after adjusting for sexual behavior; this may be explained by residual confounding for sexual behavior or by hormonal differences in immunity in men and women (Klein, 2000). Oral HPV prevalence also appears to increase with older age (Table 1), which is unusual for a sexually transmitted infection. It is unclear what is causing this unusual agerelated prevalence pattern, as higher incidence of new HPV infection among individuals over age 40 compared to teenagers and young adults is unlikely. Speculation on possible causes of this pattern includes decreased oral HPV clearance with older age or re-expression of latent infections that become re-expressed due to age-related changes in the immune system's ability to control these infections.

\section{Recurrent respiratory papillomatosis}

While a role of HPV in laryngeal cancer is unclear, HPV infection with HPV types 6 and 11 within the larynx or vocal cords can sometimes cause recurrent respiratory papillomatosis (RRP). RRP is characterized by multiple benign growths (papillomas) in the middle and lower respiratory tract. RRP is relatively uncommon, with an incidence of $0.5-4$ per 100,000 (Larson and Derkay, 2010). However, patients with this disease have significant morbidity and require many surgical procedures over years to control it, as the papillomas tend to recur after the surgeries to remove them. RRP can be fatal as the papillomas tend to grow in size and number and can cause respiratory obstruction. RRP is categorized into juvenile onset and adult onset. Juvenile onset RRP occurs in young children (usually under age five) and initial research suggests these infections may be due to vertical transmission of HPV from mother to child. Studies have reported strong associations between maternal genital condyloma at birth and increased odds of juvenile RR; (Cook et al., 1973; Hallden and Majmudar, 1986; Silverberg et al., 2003) while these children are at increased risk of RRP, the risk of transmission of genital condyloma to children during vaginal birth appears to be low ( 7 per 1000) (Silverberg et al., 2003).

RRP is defined as adult-onset when disease presents after the age of 12 years (but typically is observed in 20-40 year olds), and has been speculated to be sexually acquired. As HPV6 and HPV11, the types that cause RRP, are included in the Gardasil vaccine, cost-savings from prevention of RRP have been included in models evaluating the economic burden of HPV-related non-cervical disease (Gillison et al., 2008b; Hu and Goldie, 2008) but prevention of non-cervical endpoints has not been included in many of the models evaluating HPV vaccine cost effectiveness (de Kok et al., 2011).

\section{HPV vaccines - what is known and unknown}

\section{Proven clinical indications}

In the U.S., two HPV vaccines are currently available. The quadrivalent vaccine, Gardasil@ (HPV4), protects against infection with HPV types $-6,-11,-16$ and 18 . This vaccine was 
first licensed in 2006 for use in females ages 9-26 years old for the prevention of cervical, vaginal and vulvar cancers (U.S. Food and Drug Administration, 2011a). In 2009 licensure was expanded to also include males in this age range as clinical trial data demonstrated the vaccines effectiveness in preventing genital warts in both genders (Centers for Disease Control and Prevention (CDC), 2010b). More recent work has shown the vaccine to effectively prevent anal pre-cancers, thus the clinical indications for the vaccine have further expanded to include anal cancer prevention (Giuliano et al., 2011b; U.S. Food and Drug Administration, 2011b).

Clinical trials of the quadrivalent vaccine have demonstrated very high vaccine efficacy (>98\%) for the prevention of anal, cervical, vaginal and vulvar pre-cancers among vaccinetype-naïve individuals (reviewed in Garland and Smith, 2010 and Lu et al., 2011). As would be expected, efficacy is lower, (50-78\%) when analyses also include individuals already infected with vaccine-type HPV at the time of vaccination (Lu et al., 2011).

The second HPV vaccine, Cervarix ${ }^{\circledR}$ (HPV2), is a bivalent vaccine that provides protection against HPV types -16 and -18 . This vaccine was licensed for use in the U.S. in 2009 for the prevention of cervical cancers (U.S. Food and Drug Administration, 2009). Genital warts protection is not conferred from this vaccine because it does not contain low risk HPV types associated with this disease. Like HPV4, HPV2 has very high efficacy $(>97 \%)$ in the prevention of vaccine-type HPV-related cervical pre-cancers among HPV naïve individuals, and lower efficacy when individuals already infected with vaccine-type HPV are included in the analyses (Lu et al., 2011). HPV2 was not tested in clinical trials for efficacy against vaginal, vulvar or anal cancers/pre-cancers. Therefore, these diseases cannot be included as approved clinical indications for the vaccine. However, based on similarities in structure between HPV4 and HPV2, there is reason to believe that HPV2 will also be effective in preventing these other anogenital cancers caused by HPV-16 and -18 .

\section{U.S. vaccine recommendations}

The Advisory Committee on Immunization Practices (ACIP) is the national advisory body that develops vaccine recommendations for the U.S. population. Upon licensure of the quadrivalent vaccine for females in 2006, the ACIP recommended that all female adolescents ages 11-12 years receive the vaccine as part of routine care, with a "catch up" vaccination for females ages 13-26 years who had not been previously vaccinated, and vaccination available for females as young as age 9 if they were felt to be at high risk for infection (Markowitz et al., 2007). When licensure of the quadrivalent vaccine was expanded in 2009 to include males, the ACIP issued a "permissive" (rather than "universal") recommendation for this gender (Centers for Disease Control and Prevention (CDC), 2010b). This stance was taken primarily because of concerns that male HPV vaccination may not be cost effective, especially when compared to the impact of using financial resources to increase HPV vaccine coverage among the female population (Centers for Disease Control and Prevention (CDC), 2010b). However, most of the studies that evaluated the cost-effectiveness of male HPV vaccination at that time did not take into account the potential benefits of preventing RRP and male cancers including oropharyngeal cancers in their analyses, as these were not proven clinical endpoints at the time the permissive recommendation was made.

The permissive recommendation states that the vaccine "may be given to males aged 9 through 26 years to reduce their likelihood of acquiring genital warts" but goes on to say that the "ACIP does not recommend HPV4 for routine use among males" (Centers for Disease Control and Prevention (CDC), 2010b). Permissive vaccine recommendations, especially ones that are gender-specific, are quite uncommon. This, combined with the somewhat contradictory language of the recommendation, has anecdotally left many 
providers confused about the degree to which they should recommend the quadrivalent vaccine to their male patients. Given that recent data indicates that the quadrivalent vaccine protects against anal pre-cancers, and therefore can result in cancer-prevention benefit to males directly, the ACIP will likely continue to evaluate whether a permissive male HPV recommendation is preferable to a universal one (Giuliano et al., 2011b).

The bivalent HPV vaccine is officially approved for females ages 10-25 years old (U.S. Food and Drug Administration, 2009). However, in order to simplify HPV vaccine recommendations, the ACIP has synchronized the two vaccines' recommendations and suggest that the bivalent vaccine may also be used for females ages 9-26 years old (Centers for Disease Control and Prevention (CDC), 2010c). The ACIP does not recommend one HPV vaccine over the other, instead stating that the "ACIP recommends vaccination with HPV2 or HPV4 for the prevention of cervical cancers and precancers ... HPV4 is recommended also for prevention of genital warts" (Centers for Disease Control and Prevention (CDC), 2010c). The recommendation does, however, explicitly states that once the 3-dose HPV vaccine series is begun, the same vaccine product should be used for all doses.

\section{Remaining questions about HPV vaccines}

While much data has been gathered on the safety, efficacy, and effectiveness of HPV vaccines, many questions remain unanswered. Some of the critical issues are described below.

\section{Pre-cancer versus cancer}

Clinical trials for both HPV vaccines evaluated vaccine efficacy for cervical and/or other anogenital "pre-cancers" as the clinical endpoints. Cervical cancer's progression along several, graded, pre-cancerous states is well accepted (Schiffman and Kjaer, 2003). This progression, combined with the generally long lag time between HPV infection and cervical cancer makes cervical pre-cancer a reasonable endpoint to assess in clinical trials (Pagliusi and Aguado, 2004). In contrast, the typical progression between pre-cancerous and cancerous states for other cancers associated with HPV (e.g. HNSCC) is significantly less well established, though still highly biologically plausible and supported by preliminary available data. This uncertainty raises questions about the ultimate ability of HPV vaccines to prevent non-cervical HPV-related cancers, since this has not been tested directly. Unfortunately, this issue will not be fully addressable for another 1-2 decades, until sufficient time has passed between vaccine availability and when women might be expected to develop these diseases at a high enough rate so as to be detectable in population-based epidemiologic studies. In countries where both boys and girls are routinely being vaccinated, we may be able to evaluate the impact of HPV vaccination on HPV-related cancer among men as well, but again this question will not be addressable by population researchers for 12 decades.

\section{Impact of high versus low vaccination coverage}

A variety of mathematical models have been used to estimate HPV vaccines' impact on HPV-related disease incidence, prevalence and costs (Marra et al., 2009). However, almost all of these models used simplifying assumptions of high vaccination coverage among the targeted population - typically modeling $70-100 \%$ of adolescents having received all three doses of the HPV vaccine. Unfortunately, national studies in the U.S. demonstrate that HPV vaccination coverage is currently far below these levels. As of 2009, only 27\% of 13-17 year old females nationally had completed the HPV vaccine series (Centers for Disease Control and Prevention (CDC), 2010d). Furthermore, several studies indicate that populations at increased risk for cervical cancer are the same as those at risk for failing to be 
vaccinated (e.g. minorities) (Centers for Disease Control and Prevention (CDC), 2010d; Dempsey et al., 2011). Low overall vaccination levels combined with overlap in the populations at increased risk of HPV-related cancer and under-immunization raise significant questions about the actual impact that HPV vaccines will have on cervical cancer incidence in the US. Low female vaccination levels also have implications for policies regarding male HPV vaccination. Current policies about male HPV vaccination are based largely on cost effectiveness models that simulated high female HPV vaccine utilization. However, most studies demonstrate that the cost-effectiveness of male HPV vaccination improves substantially when the HPV vaccination coverage levels among females are low, as is currently the case in the US (Elbasha and Dasbach, 2010; Kim, 2011; Kim and Goldie, 2009). Cost-effectiveness studies will need to be continually updated as more data on the direct benefits of vaccination on reducing male HPV-related cancers and conditions becomes available.

\section{Long term vaccine efficacy}

Clinical trials for the quadrivalent vaccine have now followed women out to 5 years. These trials suggest that although measurable HPV-vaccine-type antibody titers can wane, the clinical protection afforded from vaccination remains high (Romanowski, 2011). Long duration of clinical efficacy is further supported by results from a cohort of women vaccinated with a mono-valent (HPV-16) precursor of HPV4 that demonstrate high sustained efficacy out to 8.4 years (Olsson et al., 2007; Romanowski, 2011). Studies of the bi-valent vaccine are similarly encouraging, with sustained high clinical efficacy out to 6.4 years (Romanowski, 2011). Several longer-term trials are currently underway to continue to evaluate the vaccines' effectiveness against anogenital cancers and (for HPV4) genital warts associated with vaccine-type HPV. However, such trials will not be able to assess directly whether HPV vaccine impacts other diseases such as HNSCC, which are typically diseases of individuals in their 50's and 60's. Instead, these conclusions will need to be drawn from longitudinal ecological studies comparing rates of HNSCC before and after introduction of HPV vaccines, or studies evaluating prevention of oral HPV infection among those vaccinated.

\section{Are there rare adverse events?}

Clinical trials have demonstrated that both vaccines are well tolerated, with safety profiles that are as good, if not better, than other routinely recommended vaccines (Lu et al., 2011). However parental concerns about the vaccines' safety continue to be a barrier in some communities, contributing to the low HPV vaccine utilization among U.S. adolescents (Constantine and Jerman, 2007). Many parents are adopting a "wait and see" approach before allowing their adolescent to receive the vaccine (Dempsey et al., 2009). Active monitoring of HPV vaccines' safety is a priority in many countries (Agorastos et al., 2009) and data will continue to be available for ongoing assessment of whether either vaccine is associated with rare adverse events or long term safety concerns.

\section{Conclusion}

HPV vaccines have a clear role in preventing many ano-genital cancers and conditions related to HPV infection. Overall, the high efficacy of the vaccines and excellent safety profile suggest that these vaccines will provide major health benefits to the population. As data emerges on the efficacy of these vaccines against HPV-related head and neck cancer, and ongoing studies evaluate the long term efficacy of the vaccine against both ano-genital and non-ano-genital endpoints, it is likely that an even greater benefit from these vaccines will be realized. 


\section{References}

Agius PA, Pitts MK, Smith AM, et al. Sexual behaviour and related knowledge among a representative sample of secondary school students between 1997 and 2008. Aust N Z J Public Health. 2010; 34:476-481. [PubMed: 21040175]

Agorastos T, Chatzigeorgiou K, Brotherton JM, et al. Safety of human papillomavirus (HPV) vaccines: a review of the international experience so far. Vaccine. 2009; 27:7270-7281. [PubMed: 19799849]

Ang KK, Harris J, Wheeler R, et al. Human papillomavirus and survival of patients with oropharyngeal cancer. N Engl J Med. 2010; 363:24-35. [PubMed: 20530316]

Aral SO, Patel DA, Holmes KK, et al. Temporal trends in sexual behaviors and sexually transmitted disease history among 18- to 39-year-old Seattle, Washington, residents: results of random digit-dial surveys. Sex Transm Dis. 2005; 32:710-717. [PubMed: 16254547]

Attner P, Du J, Nasman A, et al. The role of human papillomavirus in the increased incidence of base of tongue cancer. Int J Cancer. 2010; 126:2879-2884. [PubMed: 19856308]

Auluck A, Hislop G, Bajdik C, et al. Trends in oropharyngeal and oral cavity cancer incidence of human papillomavirus (HPV)-related and HPV-unrelated sites in a multicultural population: the British Columbia experience. Cancer. 2010; 116:2635-2644. [PubMed: 20336792]

Bajos N, Bozon M, Beltzer N, et al. Changes in sexual behaviours: from secular trends to public health policies. AIDS. 2010; 24:1185-1191. [PubMed: 20299962]

Brachman DG, Graves D, Vokes E, et al. Occurrence of p53 gene deletions and human papilloma virus infection in human head and neck cancer. Cancer Res. 1992; 52:4832-4836. [PubMed: 1324797]

Brandsma JL, Abramson AL. Association of papillomavirus with cancers of the head and neck. Arch Otolaryngol Head Neck Surg. 1989; 115:621-625. [PubMed: 2539843]

Centers for Disease Control Prevention (CDC). Tobacco use among middle and high school students — United States, 2000-2009. MMWR Morb Mortal Wkly Rep. 2010a; 59:1063-1068.

Centers for Disease Control Prevention (CDC). FDA licensure of quadrivalent human papillomavirus vaccine (HPV4, Gardasil) for use in males and guidance from the Advisory Committee on Immunization Practices (ACIP). MMWR Morb Mortal Wkly Rep. 2010b; 59:630-632.

Centers for Disease Control Prevention (CDC). FDA licensure of bivalent human papillomavirus vaccine (HPV2, Cervarix) for use in females and updated HPV vaccination recommendations from the Advisory Committee on Immunization Practices (ACIP). MMWR Morb Mortal Wkly Rep. 2010c; 59:626-629.

Centers for Disease Control Prevention (CDC). National, state, and local area vaccination coverage among adolescents aged 13-17 years — United States, 2009. MMWR Morb Mortal Wkly Rep. 2010d; 59:1018-1023.

Chaturvedi AK, Engels EA, Anderson WF, et al. Incidence trends for human papillomavirus-related and -unrelated oral squamous cell carcinomas in the United States. J Clin Oncol. 2008; 26:612619. [PubMed: 18235120]

Chaturvedi A, Engels E, Pfeiffer R, et al. Human papillomavirus (HPV) and rising oropharyngeal cancer incidence and survival in the United States. J Clin Oncol. 2011; 29

Constantine NA, Jerman P. Acceptance of human papillomavirus vaccination among Californian parents of daughters: a representative statewide analysis. J Adolesc Health. 2007; 40:108-115. [PubMed: 17259050]

Cook TA, Cohn AM, Brunschwig JP, et al. Wart viruses and laryngeal papillomas. Lancet. 1973; 1:782. [PubMed: 4120770]

Cruz IB, Snijders PJ, Steenbergen RD, et al. Age-dependence of human papillomavirus DNA presence in oral squamous cell carcinomas. Eur J Cancer B Oral Oncol. 1996; 32B:55-62. [PubMed: 8729620]

de Kok IM, Habbema JD, van Rosmalen J, et al. ould the effect of HPV vaccination on non-cervical HPV-positive cancers make the difference for its cost-effectiveness? Eur J Cancer. 2011; 47:428435. [PubMed: 20971633] 
Dempsey AF, Abraham LM, Dalton V, et al. Understanding the reasons why mothers do or do not have their adolescent daughters vaccinated against human papillomavirus. Ann Epidemiol. 2009; 19:531-538. [PubMed: 19394865]

Dempsey A, Cohn L, Dalton V, et al. Worsening disparities in HPV vaccine utilization among 19-26 year old women. Vaccine. 2011; 29:528-534. [PubMed: 21050904]

D’Souza G, Agrawal YJH, et al. Oral sexual behaviors associated with prevalent oral human papillomavirus (HPV) infection. J Infect Dis. 2009; 199:1-7. [PubMed: 19086812]

D'Souza G, Fakhry C, Sugar EA, et al. Six-month natural history of oral versus cervical human papillomavirus infection. Int J Cancer. 2007; 121:143-150. [PubMed: 17354235]

D’Souza G, Kreimer AR, Viscidi R, et al. Case-control study of human papillomavirus and oropharyngeal cancer. N Engl J Med. 2007; 356:1944-1956. [PubMed: 17494927]

Eaton DK, Lowry R, Brener ND, et al. Trends in human immunodeficiency virus- and sexually transmitted disease-related risk behaviors among U.S. high school students, 1991-2009. Am J Prev Med. 2011; 40:427-433. [PubMed: 21406276]

Elbasha EH, Dasbach EJ. Impact of vaccinating boys and men against HPV in the United States. Vaccine. 2010; 28:6858-6867. [PubMed: 20713101]

El-Mofty SK, Patil S. Human papillomavirus (HPV)-related oropharyngeal nonkeratinizing squamous cell carcinoma: characterization of a distinct phenotype. Oral Surg Oral Med Oral Pathol Oral Radiol Endod. 2006; 101:339-345. [PubMed: 16504868]

Engels EA, Biggar RJ, Hall HI, et al. Cancer risk in people infected with human immunodeficiency virus in the United States. Int J Cancer. 2008; 123:187-194. [PubMed: 18435450]

Fakhry C, D'Souza G, Sugar E, et al. Relationship between prevalent oral and cervical human papillomavirus infections in human immunodeficiency virus-positive and -negative women. J Clin Microbiol. 2006; 44:4479-4485. [PubMed: 17021055]

Fakhry C, Sugar E, D’Souza G, et al. Two-week versus six-month sampling interval in a short-term natural history study of oral HPV infection in an HIV-positive cohort. PLoS One. 2010; 5:e11918. [PubMed: 20689835]

Fouret P, Monceaux G, Temam S, et al. Human papillomavirus in head and neck squamous cell carcinomas in nonsmokers. Arch Otolaryngol Head Neck Surg. 1997; 123:513-516. [PubMed: 9158399]

Frisch M, Hjalgrim H, Jaeger AB, et al. Changing patterns of tonsilla squamous cell carcinoma in the United States. Cancer Causes Control. 2000; 11:489-495. [PubMed: 10880031]

Fukushima K, Ogura H, Watanabe S, et al. Human papillomavirus type 16 DNA detected by the polymerase chain reaction in non-cancer tissues of the head and neck. Eur Arch Otorhinolaryngol. 1994; 251:109-112. [PubMed: 8024757]

Garland SM, Smith JS. Human papillomavirus vaccines: current status and future prospects. Drugs. 2010; 70:1079-1098. [PubMed: 20518577]

Gillison ML. Oropharyngeal cancer: a potential consequence of concomitant HPV and HIV infection. Curr Opin Oncol. 2009; 21:439-444. [PubMed: 19587593]

Gillison ML, Chaturvedi AK, Lowy DR. HPV prophylactic vaccines and the potential prevention of noncervical cancers in both men and women. Cancer. 2008; 113:3036-3046. [PubMed: 18980286]

Gillison ML, D'Souza G, Westra W, et al. Distinct risk factor profiles for human papillomavirus type 16-positive and human papillomavirus type 16-negative head and neck cancers. J Natl Cancer Inst. 2008; 100:407-420. [PubMed: 18334711]

Gillison ML, Koch WM, Capone RB, et al. Evidence for a causal association between human papillomavirus and a subset of head and neck cancers. J Natl Cancer Inst. 2000; 92:709-720. [PubMed: 10793107]

Giuliano AR, Lee JH, Fulp W, et al. Incidence and clearance of genital human papillomavirus infection in men (HIM): a cohort study. Lancet. 2011; 377:932-940. [PubMed: 21367446]

Giuliano AR, Palefsky JM, Goldstone S, et al. Efficacy of quadrivalent HPV vaccine against HPV Infection and disease in males. N Engl J Med. 2011; 364:401-411. [PubMed: 21288094]

Hallden C, Majmudar B. The relationship between juvenile laryngeal papillomatosis and maternal condylomata acuminata. J Reprod Med. 1986; 31:804-807. [PubMed: 3772898] 
Hammarstedt L, Dahlstrand H, Lindquist D, et al. The incidence of tonsillar cancer in Sweden is increasing. Acta Otolaryngol. 2007; 127:988-992. [PubMed: 17712680]

Hammarstedt L, Lindquist D, Dahlstrand H, et al. Human papillomavirus as a risk factor for the increase in incidence of tonsillar cancer. Int J Cancer. 2006; 119:2620-2623. [PubMed: 16991119]

Hansson BG, Rosenquist K, Antonsson A, et al. Strong association between infection with human papillomavirus and oral and oropharyngeal squamous cell carcinoma: a population-based casecontrol study in southern Sweden. Acta Otolaryngol. 2005; 125:1337-1344. [PubMed: 16303684]

Heck JE, Berthiller J, Vaccarella S, et al. Sexual behaviours and the risk of head and neck cancers: a pooled analysis in the International Head and Neck Cancer Epidemiology (INHANCE) consortium. Int J Epidemiol. 2010; 39:166-181. [PubMed: 20022926]

Hemminki K, Dong C, Frisch M. Tonsillar and other upper aerodigestive tract cancers among cervical cancer patients and their husbands. Eur J Cancer Prev. 2000; 9:433-437. [PubMed: 11201683]

Herbenick D, Reece M, Schick V, et al. Sexual behavior in the United States: results from a national probability sample of men and women ages 14-94. J Sex Med. 2010; 7 (Suppl 5):255-265. [PubMed: 21029383]

Herlitz C. Sexual risk-taking in the general population of Sweden (1989-2007). Sex Health. 2009; 6:272-280. [PubMed: 19917194]

Hernandez BY, Wilkens LR, Zhu, et al. Transmission of human papillomavirus in heterosexual couples. Emerg Infect Dis. 2008; 14:888-894. [PubMed: 18507898]

Ho GY, Bierman R, Beardsley L, et al. Natural history of cervicovaginal papillomavirus infection in young women. N Engl J Med. 1998; 338:423-428. [PubMed: 9459645]

Hobbs CG, Sterne JA, Bailey M, et al. Human papillomavirus and head and neck cancer: a systematic review and meta-analysis. Clin Otolaryngol. 2006; 31:259-266. [PubMed: 16911640]

Hocking JS, Stein A, Conway EL, et al. Head and neck cancer in Australia between 1982 and 2005 show increasing incidence of potentially HPV-associated oropharyngeal cancers. Br J Cancer. 2011; 104:886-891. [PubMed: 21285981]

$\mathrm{Hu}$ D, Goldie S. The economic burden of noncervical human papillomavirus disease in the United States. Am J Obstet Gynecol. 2008; 198:500.e1-500.e7. [PubMed: 18455524]

Kim JJ. Focus on research: weighing the benefits and costs of HPV vaccination of young men. N Engl J Med. 2011; 364:393-395. [PubMed: 21288093]

Kim JJ, Goldie SJ. Cost effectiveness analysis of including boys in a human papillomavirus vaccination programme in the United States. BMJ. 2009; 339:b3884. [PubMed: 19815582]

Klein SL. The effects of hormones on sex differences in infection: from genes to behavior. Neurosci Biobehav Rev. 2000; 24:627-638. [PubMed: 10940438]

Klozar J, Kratochvil V, Salakova M, et al. HPV status and regional metastasis in the prognosis of oral and oropharyngeal cancer. Eur Arch Otorhinolaryngol. 2008; 265 (Suppl 1):S75-S82. [PubMed: 18094985]

Klussmann JP, Weissenborn SJ, Wieland U, et al. Prevalence, distribution, and viral load of human papillomavirus 16 DNA in tonsillar carcinomas. Cancer. 2001; 92:2875-2884. [PubMed: 11753961]

Koch WM, Lango M, Sewell D, et al. Head and neck cancer in nonsmokers: a distinct clinical and molecular entity. Laryngoscope. 1999; 109:1544-1551. [PubMed: 10522920]

Kreimer AR, Alberg AJ, Daniel R, et al. Oral human papillomavirus infection in adults is associated with sexual behavior and HIV serostatus. J Infect Dis. 2004; 189:686-698. [PubMed: 14767823]

Kreimer AR, Bhatia RK, Messeguer AL, et al. Oral human papillomavirus in healthyindividuals: a systematic review of theliterature. Sex Transm Dis. 2010; 37:386-391. [PubMed: 20081557]

Kreimer AR, Clifford GM, Boyle P, et al. Human papillomavirus types in head and neck squamous cell carcinomas worldwide: a systematic review. Cancer Epidemiol Biomarkers Prev. 2005; 14:467-475. [PubMed: 15734974]

Kreimer, AR.; Villa, A.; Nyitray, AG., et al. International HPV Meeting, Oral Presentation: Oral HPV Natural History among Healthy Men in the HIM Study; 2010.

Larson DA, Derkay CS. Epidemiology of recurrent respiratory papillomatosis. APMIS. 2010; 118:450-454. [PubMed: 20553527] 
Lindel K, Beer KT, Laissue J, et al. Human papillomavirus positive squamous cell carcinoma of the oropharynx: a radiosensitive subgroup of head and neck carcinoma. Cancer. 2001; 92:805-813. [PubMed: 11550151]

Lu B, Kumar A, Castellsague X, et al. Efficacy and safety of prophylactic vaccines against cervical HPV infection and diseases among women: a systematic review \& meta-analysis. BMC Infect Dis. 2011; 11:13. [PubMed: 21226933]

Markowitz LE, Dunne EF, Saraiya M, et al. Quadrivalent human papillomavirus vaccine: recommendations of the Advisory Committee on Immunization Practices (ACIP). MMWR Recomm Rep. 2007; 56:1-24. [PubMed: 17380109]

Marra F, Cloutier K, Oteng B, et al. Effectiveness and cost effectiveness of human papillomavirus vaccine: a systematic review. Pharmacoeconomics. 2009; 27:127-147. [PubMed: 19254046]

Marur S, D'Souza G, Westra WH, et al. HPV-associated head and neck cancer: a virus-related cancer epidemic. Lancet Oncol. 2010; 11(8):781-789. [Electronic publication ahead of print, 2010 May 5]. [PubMed: 20451455]

Mineta H, Ogino T, Amano HM, et al. Human papilloma virus (HPV) type 16 and 18 detected in head andneck squamous cell carcinoma. Anticancer Res. 1998; 18:4765-4768. [PubMed: 9891554]

Nasman A, Attner P, Hammarstedt L, et al. Incidence of human papillomavirus (HPV) positive tonsillar carcinoma in Stockholm, Sweden: an epidemic of viral-induced carcinoma? Int J Cancer. 2009; 125:362-366. [PubMed: 19330833]

Niedobitek G, Pitteroff S, Herbst H, et al. Detection of human papillomavirus type 16 DNA in carcinomas of the palatine tonsil. J Clin Pathol. 1990; 43:918-921. [PubMed: 2175756]

Nielson CM, Flores R, Harris RB, et al. Human papillomavirus prevalence and type distribution in male anogenital sites and semen. Cancer Epidemiol Bio-markers Prev. 2007; 16:1107-1114.

Nishioka S, Fukushima K, Nishizaki K, et al. Human papillomavirus as a risk factor for head and neck cancers-a case-control study. Acta Otolaryngol Suppl. 1999; 540:77-80. [PubMed: 10445085]

Ogura H, Watanabe S, Fukushima K, et al. Presence of human papillomavirus type 18 DNA in a pharyngeal and a laryngeal carcinoma. Jpn J Cancer Res. 1991; 82:1184-1186. [PubMed: 1661280]

Olsson SE, Villa LL, Costa RL, et al. Induction of immune memory following administration of a prophylactic quadrivalent human papillomavirus (HPV) types 6/11/16/18L1 virus-like particle (VLP) vaccine. Vaccine. 2007; 25:4931-4939. [PubMed: 17499406]

Pagliusi SR, Aguado M Teresa. Efficacy and other milestones for human papillomavirus vaccine introduction. Vaccine. 2004; 23:569-578. [PubMed: 15630792]

Pierce JP, Messer K, White MM, et al. Prevalence of heavy smoking in California and the United States, 1965-2007. JAMA. 2011; 305:1106-1112. [PubMed: 21406647]

Pintos J, Black MJ, Sadeghi N, et al. Human papillomavirus infection and oral cancer: a case-control study in Montreal, Canada. Oral Oncol. 2008; 44:242-250. [PubMed: 17467327]

Reimers N, Kasper HU, Weissenborn SJ, et al. Combined analysis of HPV-DNA, p16 and EGFR expression to predict prognosis in oropharyngeal cancer. Int J Cancer. 2007; 120:1731-1738. [PubMed: 17236202]

Ringstrom E, Peters E, Hasegawa M, et al. Human papillomavirus type 16 and squamous cell carcinoma of the head and neck. Clin Cancer Res. 2002; 8:3187-3192. [PubMed: 12374687]

Rintala MA, Grenman SE, Jarvenkyla ME, et al. High-risk types of human papillomavirus (HPV) DNA in oral and genital mucosa of infants during their first 3 years of life: experience from the Finnish HPV Family Study. Clin Infect Dis. 2005; 41:1728-1733. [PubMed: 16288396]

Rintala M, Grenman S, Puranen M, et al. Natural history of oral papillomavirus infections in spouses: a prospective Finnish HPV Family Study. J Clin Virol. 2006; 35:89-94. [PubMed: 16112613]

Ritchie JM, Smith EM, Summersgill KF, et al. Human papillomavirus infection as a prognostic factor in carcinomas of the oral cavity and oropharynx. Int J Cancer. 2003; 104:336-344. [PubMed: 12569557]

Romanitan M, Nasman A, Ramqvist T, et al. Human papillomavirus frequency in oral and oropharyngeal cancer in Greece. Anticancer Res. 2008; 28:2077-2080. [PubMed: 18751378]

Romanowski B. Long term protection against cervical infection with the human papillomavirus: review of currently available vaccines. Hum Vaccin. 2011; 7 
Ryerson AB, Peters ES, Coughlin SS, et al. Burden of potentially human papillomavirus-associated cancers of the oropharynx and oral cavity in the US, 1998-2003. Cancer. 2008; 113:2901-2909. [PubMed: 18980273]

Saini R, Khim TP, Rahman SA, et al. High-risk human papillomavirus in the oral cavity of women with cervical cancer, and their children. Virol J. 2010; 7:131. [PubMed: 20550718]

Santelli JS, Lindberg LD, Abma J, et al. Adolescent sexual behavior: estimates and trends from four nationally representative surveys. Fam Plann Perspect. 2000; 32:156-165. 194. [PubMed: 10942351]

Santelli JS, Orr M, Lindberg LD, et al. Changing behavioral risk for pregnancy among high school students in the United States, 1991-2007. J Adolesc Health. 2009; 45:25-32. [PubMed: 19541246]

Satterwhite CL, Kamb ML, Metcalf C, et al. Changes in sexual behavior and STD prevalence among heterosexual STD clinic attendees: 1993-1995 versus 1999-2000. Sex Transm Dis. 2007; 34:815819. [PubMed: 17551414]

Schiffman M, Kjaer SK. Chapter 2: natural history of anogenital human papillomavirus infection and neoplasia. J Natl Cancer Inst Monogr. 2003; 31:14-19. [PubMed: 12807940]

Schwartz SM, Daling JR, Doody DR, et al. Oral cancer risk in relation to sexual history and evidence of human papillomavirus infection. J Natl Cancer Inst. 1998; 90:1626-1636. [PubMed: 9811312]

Settle K, Posner MR, Schumaker LM, et al. Racial survival disparity in head and neck cancer results from low prevalence of human papillomavirus infection in black oropharyngeal cancer patients. Cancer Prev Res (Phila). 2009; 2:776-781. [PubMed: 19641042]

Silverberg MJ, Thorsen P, Lindeberg H, et al. Condyloma in pregnancy is strongly predictive of juvenile-onset recurrent respiratory papillomatosis. Obstet Gynecol. 2003; 101:645-652. [PubMed: 12681865]

Smith EM, Ritchie JM, Summersgill KF, et al. Age, sexual behavior and human papillomavirus infection in oral cavity and oropharyngeal cancers. Int J Cancer. 2004; 108:766-772. [PubMed: 14696105]

Smith EM, Ritchie JM, Yankowitz J, et al. HPV prevalence and concordance in the cervix and oral cavity of pregnant women. Infect Dis Obstet Gynecol. 2004; 12:45-56. [PubMed: 15739817]

Smith EM, Swarnavel S, Ritchie JM, et al. Prevalence of human papillomavirus in the oral cavity/ oropharynx in a large population of children and adolescents. Pediatr Infect Dis J. 2007; 26:836840. [PubMed: 17721381]

Snijders PJ, Scholes AG, Hart CA, et al. Prevalence of mucosotropic human papillomaviruses in squamous-cell carcinoma of the head and neck. Int J Cancer. 1996; 66:464-469. [PubMed: 8635861]

Strome SE, Savva A, Brissett AE, et al. Squamous cell carcinoma of the tonsils: a molecular analysis of HPV associations. Clin Cancer Res. 2002; 8:1093-1100. [PubMed: 11948119]

Tachezy R, Klozar J, Rubenstein L, et al. Demographic and risk factors in patients with head and neck tumors. J Med Virol. 2009; 81:878-887. [PubMed: 19319944]

Tachezy R, Klozar J, Salakova M, et al. HPV and other risk factors of oral cavity/oropharyngeal cancer in the Czech Republic. Oral Dis. 2005; 11:181-185. [PubMed: 15888110]

Termine N, Giovannelli L, Matranga D, et al. Oral human papillomavirus infection in women with cervical HPV infection: new data from an Italian cohort and a metanalysis of the literature. Oral Oncol. 2011; 47:244-250. [PubMed: 21429788]

Turner CF, Danella RD, Rogers SM. Sexual behavior in the United States 1930-1990: trends and methodological problems. Sex Transm Dis. 1995; 22:173-190. [PubMed: 7652662]

U.S. Food and Drug Administration. [Accessed November 30, 2009] FDA News Release: FDA approved new vaccine for prevention of cervical cancer [Online]. Available at: http://www.fda.gov/NewsEvents/Newsroom/PressAnnouncements/ucm.187048.htm

U.S. Food and Drug Administration, a. [Accessed May 10, 2011] FDA Licenses Quadrivalent Human Papillomavirus (Types 6, 11, 16, 18) Recombinant Vaccine (Gardasil) for the Prevention of Cervical Cancer and Other Diseases in Females Caused by Human Papillomavirus [Online]. Available at: http://www.fda.gov/AboutFDA/CentersOffices/CDER/ucm095647.htm 
U.S. Food and Drug Administration, b. Gardasil approved to prevent anal cancer [Online]. Available at: http://www.fda.gov/NewsEvents/Newsroom/PressAnnouncements/ucm237941.htmJan 2, 20011

van Houten VM, Snijders PJ, van den Brekel MW, et al. Biological evidence that human papillomaviruses are etiologically involved in a subgroup of head and neck squamous cell carcinomas. Int J Cancer. 2001; 93:232-235. [PubMed: 11410871]

Warren CW, Santelli JS, Everett SA, et al. Sexual behavior among U.S. high school students, 19901995. Fam Plann Perspect. 1998; 30:170-172. 200. [PubMed: 9711454] 


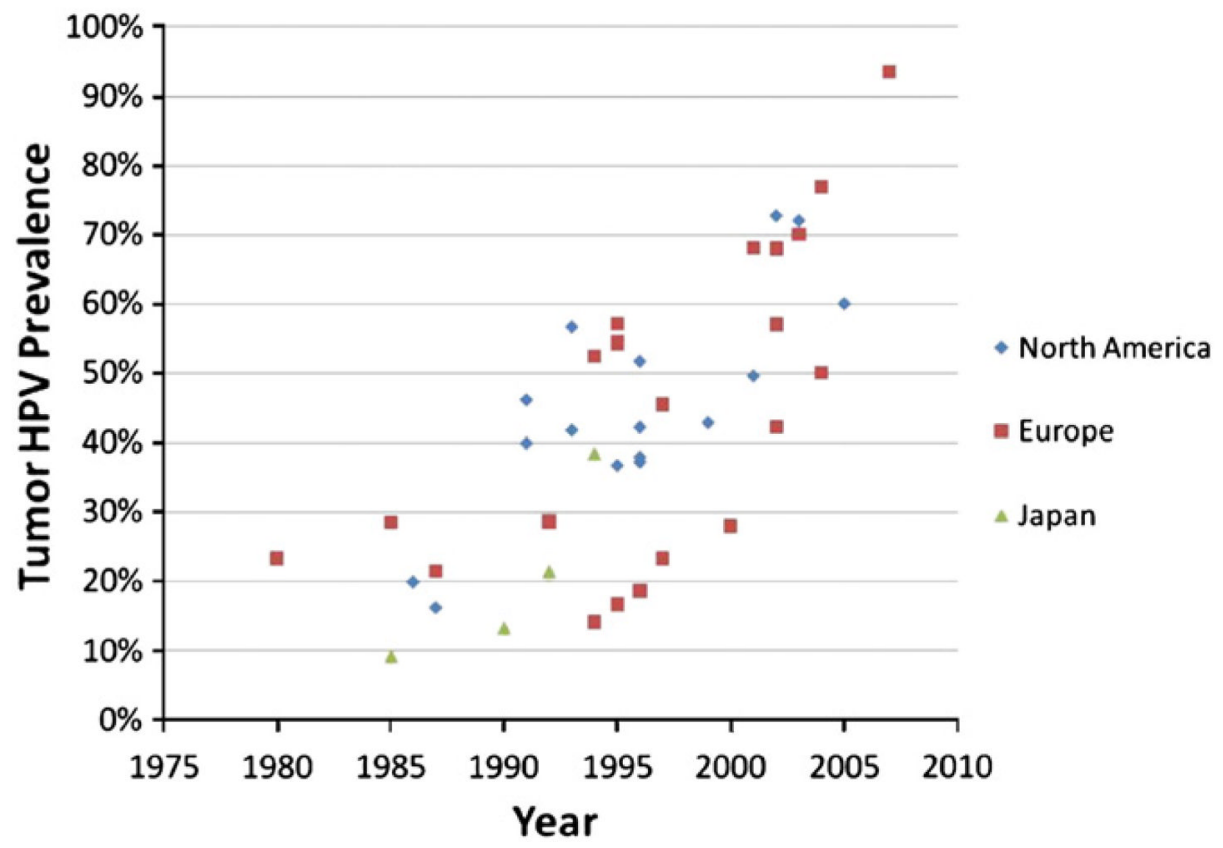

Fig. 1.

Summary of the prevalence of HPV in tumor of oropharyngeal cancer cases reported in the literature by calendar time of case diagnosis and geographic region. Graphed by the median year of case enrollment in each study and restricted to studies which enrolled cases within 11 years or less (or reported HPV prevalence within calendar year strata of 10 years of less). Studies referenced in the figure include cases diagnosed during the 1970's (Hammarstedt et al., 2006), 1980's (Brandsma and Abramson, 1989; Chaturvedi et al., 2011; Hammarstedt et al., 2006; Niedobitek et al., 1990; Ogura et al., 1991), 1990's (Brachman et al., 1992; Cruz et al., 1996; Fouret et al., 1997; Fukushima et al., 1994; Gillison et al., 2000; Hammarstedt et al., 2006; Koch et al., 1999; Mineta et al., 1998; Nishioka et al., 1999; Reimers et al., 2007; Ringstrom et al., 2002; Ritchie et al., 2003; Romanitan et al., 2008; Smith et al., 2004a; Snijders et al., 1996; Strome et al., 2002), 2001-2003 (Hammarstedt et al., 2006; Hansson et al., 2005; Klozar et al., 2008; Klussmann et al., 2001; Lindel et al., 2001; Pintos et al., 2008; Settle et al., 2009; Tachezy et al., 2005; van Houten et al., 2001), and 20042009 (Chaturvedi et al., 2011; D'Souza et al., 2007a; El-Mofty and Patil, 2006; Nasman et al., 2009; Romanitan et al., 2008; Tachezy et al., 2009) (Chaturvedi et al., 2011; D'Souza et al., 2007a; El-Mofty and Patil, 2006; Nasman et al., 2009; Romanitan et al., 2008; Tachezy et al., 2009). 


\begin{tabular}{|c|c|c|c|c|c|c|c|c|c|c|c|c|}
\hline & 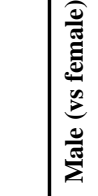 & & $\begin{array}{l}\widehat{r} \\
\infty \\
i \\
\hat{0} \\
0 \\
n \\
i\end{array}$ & i & 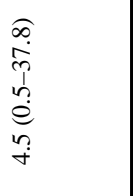 & : & $\begin{array}{l}\hat{m} \\
\dot{0} \\
2 \\
\dot{\rho} \\
\stackrel{-}{-}\end{array}$ & & & \begin{tabular}{|l}
0 \\
0 \\
0 \\
01 \\
0 \\
0 \\
$\vdots$ \\
0 \\
0
\end{tabular} & 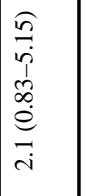 & \\
\hline & 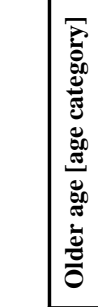 & & 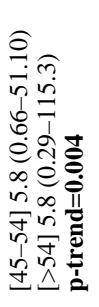 & 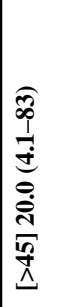 & 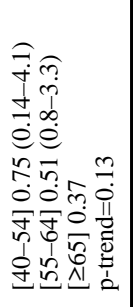 & 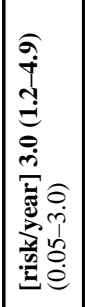 & 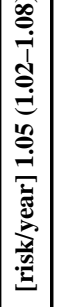 & 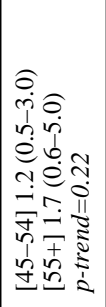 & 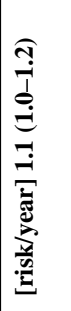 & & 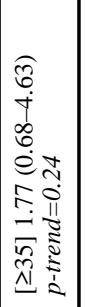 & \\
\hline & 已| & & 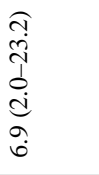 & $\mid \begin{array}{c}6 \\
0 \\
i \\
n \\
n \\
0 \\
\infty \\
\infty \\
0 \\
0\end{array}$ & 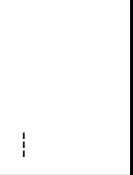 & 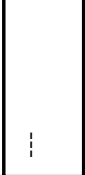 & 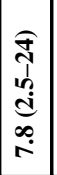 & 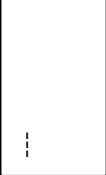 & 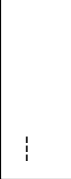 & 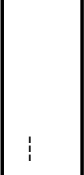 & 1 & \\
\hline 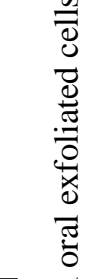 & 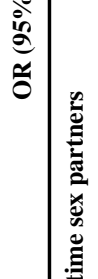 & 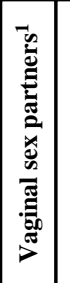 & 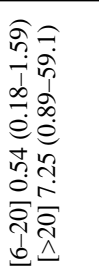 & : & 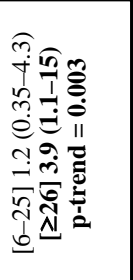 & 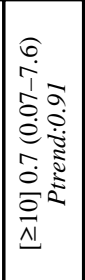 & 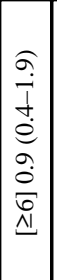 & 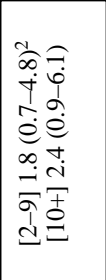 & 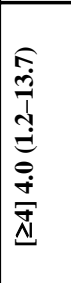 & 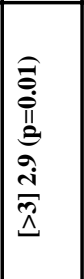 & & \\
\hline 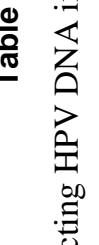 & 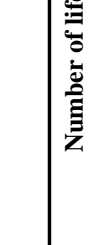 & 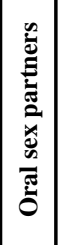 & : & : & 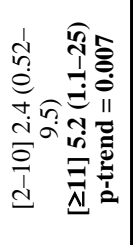 & 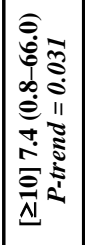 & 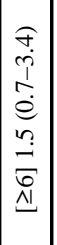 & : & 1 & 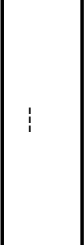 & & 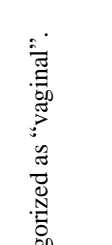 \\
\hline 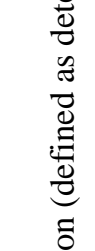 & 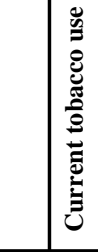 & & 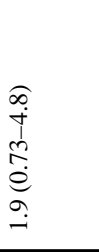 & 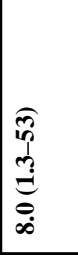 & 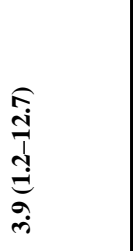 & i & 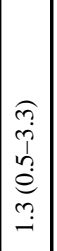 & 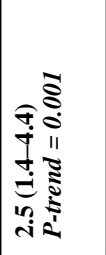 & 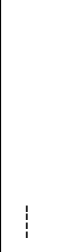 & 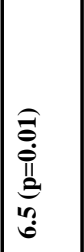 & & 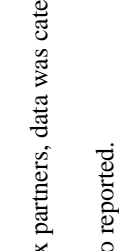 \\
\hline 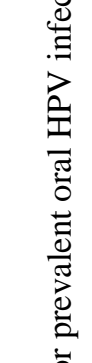 & 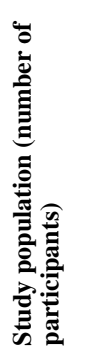 & & 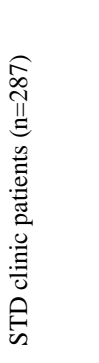 & 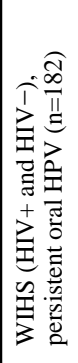 & 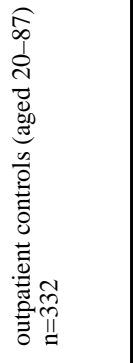 & 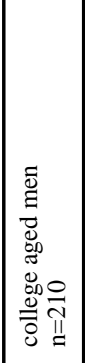 & 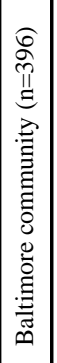 & 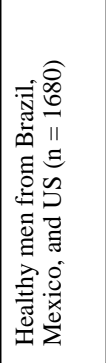 & 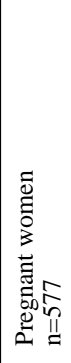 & 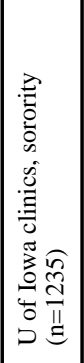 & 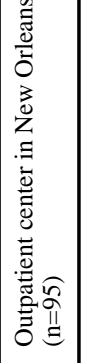 & 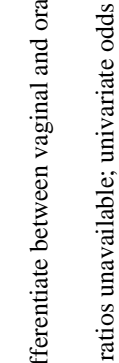 \\
\hline 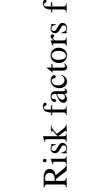 & 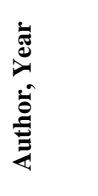 & & $\begin{array}{l}\hat{\sigma} \\
\bar{z} \\
\bar{z}\end{array}$ & \begin{tabular}{|l}
$\hat{O}$ \\
$\tilde{N}$ \\
$\tilde{N}$ \\
$\tilde{\Xi}$ \\
0 \\
0 \\
0
\end{tabular} & 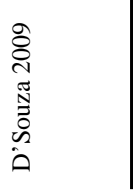 & 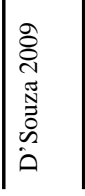 & 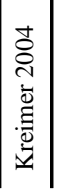 & 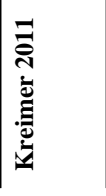 & 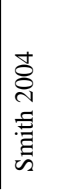 & 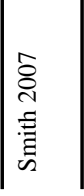 & 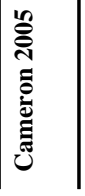 & 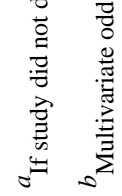 \\
\hline
\end{tabular}

